Rev. Biol. Neotrop. 4(1): 1-12. 2007

\title{
elastomataceae da SerRa de São José, Minas Gerais
}

\author{
Rosana Augstroze Rutter Drummond \\ Museu Nacional/UFRJ, Departamento de Botânica, Laboratório de Taxonomia de Faneróga- \\ mas, Rio de Janeiro, RJ, E-mail: rosanaard@yahoo.com.br
}

\begin{abstract}
Ruy José Válka Alves
Museu Nacional/UFRJ, Departamento de Botânica, Laboratório de Taxonomia de Fanerógamas, Rio de Janeiro, RJ, Brasil, E-mail:ruyvalka@yahoo.com.br

Cristiana Koschnitzke

Museu Nacional/UFRJ, Departamento de Botânica, Laboratório de Biologia Reprodutiva de Angiospermas, Rio de Janeiro, RJ, E-mail: criskos@mn.ufrj.br
\end{abstract}

\begin{abstract}
Resumo: Apresenta-se uma lista das espécies da família Melastomataceae na Serra de São José, localizada em grande parte nos municípios de Tiradentes e Prados, no sudeste do estado de Minas Gerais, Brasil. As coletas foram realizadas principalmente em Campo rupestre e Cerrado. A listagem dos gêneros e espécies ocorrentes na Serra de São José foi comparada com as listagens de Melastomataceae de algumas floras rupestres publicadas para Minas Gerais, Bahia e Escudo das Guianas. Foram encontrados 17 gêneros e 57 espécies de Melastomataceae, uma riqueza considerável para uma área de apenas 30 $\mathrm{km}^{2}$. Foram registrados os gêneros Miconia (15 espécies), Tibouchina (9), Leandra (8), Microlicia (7), Trembleya (3), Cambessedesia (2), Chaetostoma (2), Rhynchanthera (2), Acisanthera, Clidemia, Comolia, Lavoisiera, Macairea, Marcetia, Ossaea, Siphanthera e Svitramia (uma espécie de cada). Leandra australis (Cham.) Cogn., espécie do sul do Brasil,é reportada pela primeira vez para o estado de Minas Gerais; também foi registrada uma nova espécie de Cambessedesia.
\end{abstract}

Palavras-chave: Florística, Melastomataceae, Minas Gerais, Serra de São José.

Aвstract: In this study a list of species from the Melastomataceae family occurring in São José range, mostly located in Tiradentes and Prados municipalities, in the southeastern part of the state of Minas Gerais, Brazil, is presented. The samples were collected mainly in Campo rupestre and Cerrado formations. The list of genera and species found in São José range was compared with lists of Melastomataceae from some campo rupestre ranges published for Minas Gerais and Bahia states and the Guyana Shield. In this study 17 genera and 57 species of Melastomataceae were found, which is a considerable richness for an area of only $30 \mathrm{~km}^{2}$. Thes following genera were registered: Miconia (15 species), Tibouchina (9), Leandra (8), Microlicia (7), Trembleya (3), Cambessedesia (2), Chaetostoma (2), Rhynchanthera (2), Acisanthera, Clidemia, Comolia, Lavoisiera, Macairea, Marcetia, Ossaea, Siphanthera, and Svitramia (one species each). Leandra australis (Cham.)Cogn., a species from Southern Brazil, was reported for the first time for the state of Minas Gerais; also, a new species of Cambessedesia was registered.

KeY words: Floristic, Melastomataceae, Minas Gerais, Serra de São José.

\section{INTRODUÇÃO}

\section{A família Melastomataceae é consti-} tuída por 166 gêneros, com cerca de 4.570 espécies, e apresenta distribuição pantropical, sendo sua maior concentração no Novo Mundo, com cerca de 2.950 espécies (Clausing \& Renner, 2001). No Brasil, são encontrados 65 gêneros (Renner, 1993), com mais de 1.500 espécies (Romero, 2000).
As Melastomataceae formam um grupo monofilético, apoiado morfologicamente pela venação acródroma das folhas. A família parece ser o maior clado de angiospermas caracterizado por esse tipo de venação (Clausing \& Renner, 2001). Além dessa, as principais características da família são as flores geralmente actinomorfas, perigíneas ou epigíneas, 
com um hipanto em forma de taça, em cujo ápice se inserem as lacínias do cálice, pétalas e estames e as anteras poricidas com conectivos espessados e/ou prolongados.

Segundo Drummond et al. (2005), a Serra de São José (SSJ) é assinalada como área de importância biológica extrema pela alta riqueza em plantas ameaçadas, invertebrados de distribuição restrita e alta riqueza de aves.

O objetivo do presente estudo é apresentar uma lista das espécies de Melastomataceae da Serra de São José, em Tiradentes, Minas Gerais, principalmente dos ambientes de Campo rupestre e Cerrado. Também é apresentada uma comparação quantitativa entre a riqueza da família na Serra de São José com a de outras áreas de Minas Gerais, Bahia e Escudo das Guianas, pretendendo contribuir para o conhecimento sobre a flora da Serra de São José e a distribuição geográfica dessas espécies e para a verificação da existência de espécies em comum.

\section{Material e mÉtodos}

A Serra de São José está localizada acima do Trópico de Capricórnio, entre as coordenadas $21^{\circ} 3-7^{\prime} \mathrm{S}$ e $44^{\circ}$ 6-13' W, em Minas Gerais, a nordeste do município de Tiradentes e a oeste do de Prados. Ocupa uma área de aproximadamente $30 \mathrm{~km}^{2}$, com elevações a partir de $900 \mathrm{~m}$ e atinge $1.430 \mathrm{~m}$ em seu pico mais alto. Cerca de $20 \mathrm{~km}^{2}$ da área da Serra de São José encontra-se dentro da Área de Proteção Ambiental (APA) Estadual da Serra de São José, criada em 16 de fevereiro de 1990, devido à imensa riqueza de espécies ali encontrada (Alves, 1997).

O principal componente das rochas na Serra de São José é o quartzito em numerosas texturas (Ribeiro, 1996). Lá ocorrem Campos rupestres, Cerrado, Matas de galeria e uma floresta densa e heterogênea que cobre a porção sul, mas a vegetação predominante é a de Campo rupestre, que cobre as maiores altitudes da Serra, entre $950 \mathrm{~m}$ e $1.430 \mathrm{~m}$.

Como o Professor Ruy Alves já vinha trabalhando com coletas desde 1986 para o levantamento geral da flora da Serra de São José, foram realizadas cinco viagens complementares entre agosto de 2003 e março de 2005. As coletas foram realizadas principalmente no Campo rupestre e no Cerrado, tendo também sido coletadas espécies de borda de mata ou ao longo das trilhas que cortam a mata da face sul e que levam a áreas de Cerrado ou Campo rupestre.

A identificação dos espécimes na Serra de São José foi feita por meio de chaves analíticas disponíveis em trabalhos recentes de revisão ou florística (Goldenberg, 2000; Guimarães, 1997; Koschnitzke \& Martins, 2006; Martins, 1984, 1989; Martins , et al., 1996; Martins, 1997; Matsumoto, 1999; Renner, 1989, 1990, 1994; Romero, 2000; Souza, 1998), sendo eventualmente utilizadas as chaves de Cogniaux (1883-1885, 1886-1888). Foram feitas comparações com material depositado nos herbários R, RB, SPF e UEC, siglas de acordo com o Index herbariorum (Holmgren et al., 1990) e com as descrições originais das espécies. Entre os especialistas na família, os Profs. Drs. Angela Borges Martins, Cristiana Koschnitzke, Frank Almeda, Paulo Guimarães, Renato Goldenberg e Susanne S. Renner contribuíram com algumas identificações.

As coletas foram depositadas no Herbário do Museu Nacional (R), com algumas duplicatas nos herbários da Universidade Estadual de Campinas (UEC) e da Universidade Federal do Paraná (UPCB).

Por terem sido observadas formações vegetacionais semelhantes às existentes em outras áreas rupestres foram realizadas comparações utilizando-se como base materiais depositados nos herbários e a literatura disponível sobre as localidades selecionadas: Serra da Canastra (Romero, 2000), Serra de Carrancas (Matsumoto, 1999) e Serra do Cipó (Semir et al., 1987) em Minas Gerais, de Catolés (Zappi et al., 2003) e Pico das Almas (Baumgratz et al., 1995) na Bahia e Escudo das Guianas na Venezuela (Berry et al., 2001)(Figura 1)

\section{Resultados e discussão}

Na Serra de São José, a família Melastomataceae é a quarta maior família (Alves 1992), tendo sido encontradas 56 espécies pertencentes a 17 gêneros (Tabela 1): Miconia (14 espécies), Tibouchina (9), Leandra (8), Microlicia (7), Trembleya (3), Cambessedesia, Chaetostoma e 
Rhynchanthera (2 espécies cada) e Acisanthera, Clidemia, Comolia, Lavoisiera, Macairea, Marce- tia, Ossaea, Siphanthera e Svitramia (1 espécie cada).

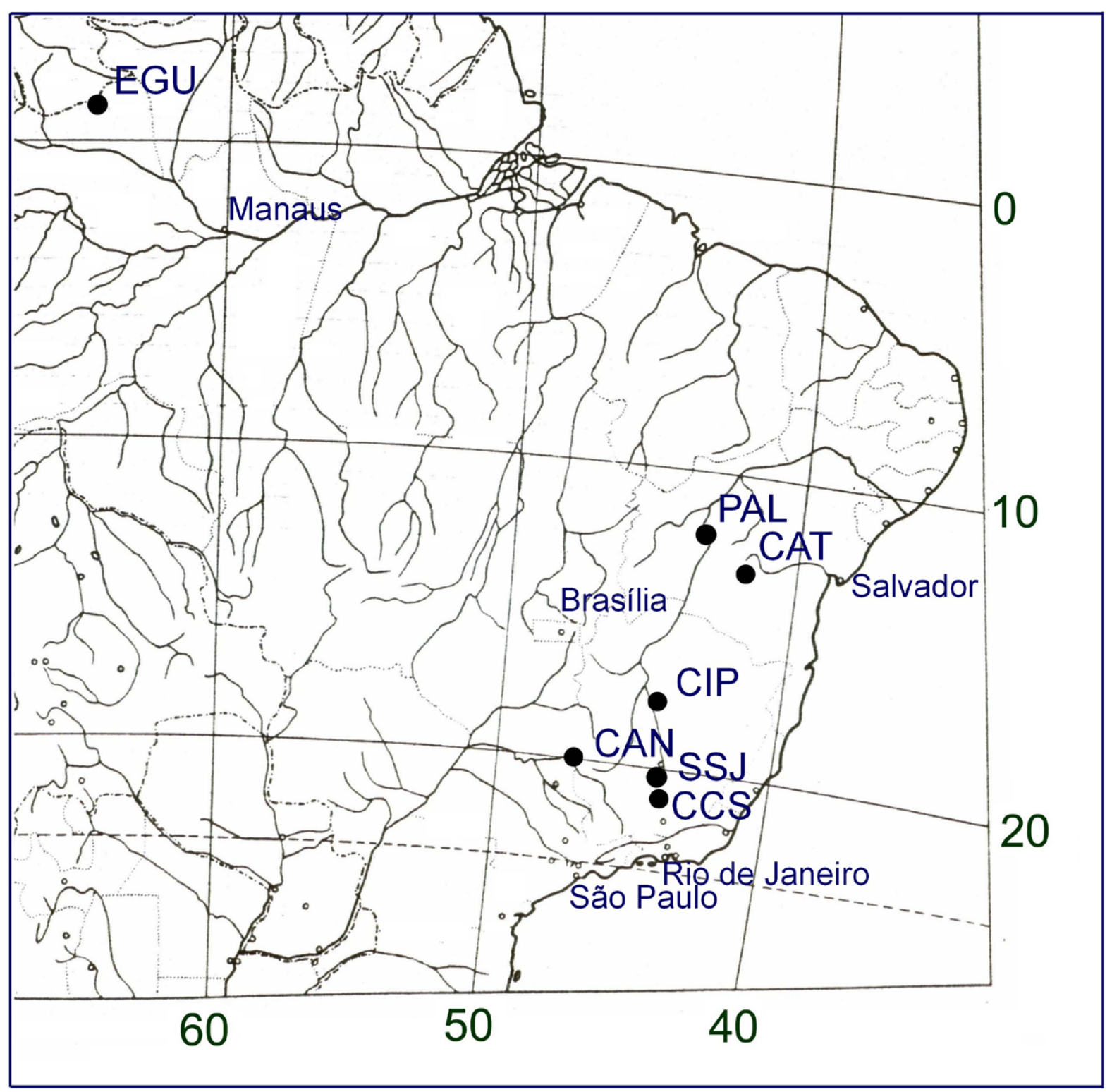

Figura 1 - Mapa de localização das áreas comparadas. No estado de Minas Gerais: Serra de São José (SSJ), Serra da Canastra (CAN), Serra de Carrancas (CCS) e Serra do Cipó (CIP). No estado da Bahia: Catolés (CAT) e Pico das Almas (PAL). Na Venezuela: Escudo das Guianas (EGU). 
Tabela 1 - Lista das espécies de Melastomataceae da Serra de São José, ambiente (AMB) onde ocorrem (CR Campo rupestre; $\mathrm{C}$-Cerrado; $\mathrm{BM}$ - borda de mata e $\mathrm{M}$ - mata) e presença das espécies nas Serras da Canastra (CAN), Carrancas (CAR) e Cipó (CIP), Catolés (CAT), Pico das Almas (PAL) e Escudo das Guianas (EGU). (Sigla do Herbário, Holmgren, 1990).

\begin{tabular}{|c|c|c|c|c|c|c|c|}
\hline ESPÉCIES & AMB & CAR & CAN & CIP & CAT & PAL & EGU \\
\hline Acisanthera variabilis (Mart.) Triana & $\mathrm{CR} / \mathrm{C}$ & $x$ & & & & & \\
\hline Cambessedesia sp. & CR & & & & & & \\
\hline $\begin{array}{l}\text { Cambessedesia espora (A. St. Hil. ex Bonpl.) } \\
\text { subsp. ilicifolia (DC.) A.B.Martins }\end{array}$ & CR & $x$ & & $(R)$ & & & \\
\hline $\begin{array}{l}\text { Chaetostoma albiflorum (Naudin) Kosch. \& } \\
\text { A.B.Martins } \\
\text { Chaetostoma cupressinum (D.Don) Kosch. \& } \\
\text { A.B.Martins }\end{array}$ & $\begin{array}{l}\mathrm{CR} \\
\mathrm{CR}\end{array}$ & $x$ & & & & & \\
\hline Clidemia sericea D.Don & $\mathrm{CR}$ & $x$ & & & & & $x$ \\
\hline Comolia sertularia Triana & $\mathrm{CR}$ & & & $(\mathrm{SPF})$ & & & \\
\hline Lavoisiera imbricata Benth. & $\mathrm{CR}$ & $x$ & $x$ & & $x$ & $x$ & \\
\hline Leandra adenothrix Cogn. & BM & & & & & & \\
\hline Leandra aurea (Cham.) Cogn. & CR & $x$ & $x$ & $x$ & $x$ & $x$ & \\
\hline Leandra australis (Cham.) Cogn. & BM & & & & & & \\
\hline Leandra cancellata Cogn. & BM & & & & $x$ & & \\
\hline Leandra coriacea Cogn. & $\mathrm{CR} / \mathrm{C}$ & & $x$ & & & & \\
\hline Leandra melastomoides Raddi & M/BM & & $x$ & & $x$ & $x$ & \\
\hline Leandra pennipilis Cogn. & $\mathrm{CR}$ & & & & & & \\
\hline Leandra polychaeta Cogn. & BM & & & $(\mathrm{RB})$ & & & \\
\hline Macairea radula (Bonpl.) DC. & $\mathrm{CR} / \mathrm{C}$ & & $x$ & $x$ & $x$ & $x$ & \\
\hline Marcetia taxifolia (A. St. Hil.) DC. & $\mathrm{CR}$ & $x$ & $x$ & $x$ & $x$ & $x$ & \\
\hline Miconia albicans (SW.) Triana & $\mathrm{CR} / \mathrm{C}$ & $x$ & $x$ & $x$ & $x$ & $x$ & $x$ \\
\hline Miconia brunnea Mart. ex DC. & M & & & & & & \\
\hline Miconia chamissois Naudin & C & $x$ & $x$ & $x$ & $x$ & $\mathrm{x}$ & \\
\hline Miconia cinnamomifolia (DC.) Naudin & M & & & & & & \\
\hline Miconia ferruginata DC. & C & $x$ & $\mathrm{x}$ & $x$ & $\mathrm{x}$ & $\mathrm{x}$ & \\
\hline Miconia ibaguensis (Bonpl.) Triana & BM & & $\mathrm{x}$ & & & & $x$ \\
\hline Miconia ligustroides (DC.) Naudin & C/BM & $x$ & $\mathrm{x}$ & & $\mathrm{x}$ & $\mathrm{x}$ & \\
\hline Miconia pepericarpa DC. & $\begin{array}{l}\text { C R / } \\
\text { BM }\end{array}$ & $x$ & $x$ & $x$ & $x$ & $x$ & \\
\hline Miconia rubiginosa (Bonpl.) DC. & $\mathrm{C}$ & $x$ & $\mathrm{x}$ & $x$ & & & $\mathrm{x}$ \\
\hline Miconia sellowiana Naudin & $\begin{array}{l}\mathrm{CR} / \mathrm{C} / \\
\mathrm{BM}\end{array}$ & & $x$ & & & & \\
\hline Miconia stenostachya DC. & BM & $x$ & $\mathrm{x}$ & $\mathrm{x}$ & $\mathrm{x}$ & $\mathrm{x}$ & $\mathrm{x}$ \\
\hline
\end{tabular}


Tabela 1 - Continuação

\begin{tabular}{|c|c|c|c|c|c|c|c|}
\hline ESPÉCIES & AMB & CAR & CAN & CIP & CAT & PAL & EGU \\
\hline Miconia theaezans (Bonpl.) Cogn. & $\begin{array}{l}\mathrm{C} R / \\
\mathrm{BM}\end{array}$ & $\mathrm{X}$ & $\mathrm{X}$ & $\mathrm{x}$ & $\mathrm{x}$ & $\mathrm{x}$ & $\mathrm{X}$ \\
\hline Microlicia avicularis (Naud.) Mart. & $\mathrm{CR}$ & & & $\mathrm{x}$ & & & \\
\hline Microlicia decussata Naudin & $\mathrm{CR}$ & & & & & & \\
\hline Microlicia euphorbioides Mart. & $\mathrm{C} / \mathrm{CR}$ & $\mathrm{x}$ & $\mathrm{X}$ & & & & \\
\hline Microlicia fasciculata Mart. & $\mathrm{C} / \mathrm{CR}$ & $x$ & $\mathrm{X}$ & $(\mathrm{R})$ & & $\mathrm{x}$ & \\
\hline Microlicia fulva (Spreng.) Cham. & $\mathrm{CR}$ & $x$ & $\mathrm{x}$ & $\mathrm{x}$ & & $\mathrm{x}$ & \\
\hline Microlicia glandulifera Cogn. & $\mathrm{CR}$ & $x$ & & & & & \\
\hline Microlicia isophylla DC. & $\mathrm{CR}$ & $x$ & $\mathrm{x}$ & & & $\mathrm{x}$ & \\
\hline Ossaea amygdaloides (DC.) Triana & BM & & $\mathrm{x}$ & & & & \\
\hline Rhynchanthera cordata DC. & $\mathrm{C} / \mathrm{CR}$ & & & & & & \\
\hline Rhynchanthera grandiflora(Aubl.) DC. & C & $x$ & $x$ & $(\mathrm{R})$ & $x$ & & \\
\hline Siphanthera arenaria Cogn. & CR & & & $(\mathrm{R})$ & & & \\
\hline Svitramia pulchra Cham. & $\mathrm{CR}$ & $x$ & $x$ & & & & \\
\hline Tibouchina candolleana (DC.) Cogn. & BM & & $x$ & $x$ & $x$ & $x$ & \\
\hline Tibouchina estrellensis (Raddi) Cogn. & BM & & $x$ & & & & \\
\hline Tibouchina fothergillae Cogn. & BM & & $x$ & & & & \\
\hline Tibouchina frigidula Cogn. & CR & $x$ & $x$ & $x$ & & & \\
\hline Tibouchina gracilis (Bonpl.) Cogn. & $\mathrm{C} / \mathrm{BM}$ & $x$ & $\mathrm{X}$ & $x$ & & & $\mathrm{x}$ \\
\hline Tibouchina herbacea (DC.) Cogn. & C & $x$ & $\mathrm{x}$ & & & & \\
\hline Tibouchina heteromalla(D.Don) Cogn. & $\mathrm{CR} / \mathrm{C}$ & $x$ & $\mathrm{X}$ & $x$ & & & \\
\hline Tibouchina martialis (Cham.) Cogn. & $\mathrm{CR}$ & $x$ & $\mathrm{x}$ & & & & \\
\hline Tibouchina stenocarpa (DC.) Cogn. & $\mathrm{CR}$ & $x$ & $\mathrm{x}$ & $(\mathrm{RB})$ & & & \\
\hline Trembleya parviflora (D.Don) Cogn. & $\mathrm{CR}$ & $x$ & $\mathrm{X}$ & $\mathrm{x}$ & $x$ & $x$ & \\
\hline Trembleya phlogiformis DC. & $\mathrm{CR}$ & $x$ & $\mathrm{X}$ & $x$ & & & \\
\hline Trembleya tridentata Naudin & CR & & & & & & \\
\hline
\end{tabular}




\section{Chave analítica para os gêneros e espécies de Melastomatacea da Serra de São José}

1. Terófitas, ervas

Siphanthera arenaria

1. Fanerófitas, subarbustos, arbustos, árvores.

2. Androceu com apenas um verticilo fértil, com estaminódios

Rhynchanthera

3. Arbusto glutinoso, densamente hirsuto-glanduloso, tricomas até $1,5 \mathrm{~mm}$, corola actinomorfa, hipanto com 5,0-7,0 mm, lacínias do cálice com 9,0-10,0 mm R. grandiflora

3. Arbusto não glutinoso, hirsuto e esparsamente viloso- adpresso, tricomas até $3,0 \mathrm{~mm}$, corola zigomorfa, hipanto com 3,5-4,0 mm, lacínias do cálice com 2,5-4,0 mm

R. cordata

2. Androceu com os dois verticilos férteis, sem estaminódios

4. Folhas carenadas.

5. Flores 5-meras, pétalas amarelas ou brancas, hipanto com coroa radial de tricomas no ápice, fruto cápsula com deiscência do ápice para a base

Chaetostoma

6. Pétalas brancas, lâminas com até 5,0 mm, lacínias estreitamente triangulares a subuladas

C. albiflorum

6. Pétalas amarelas, lâminas com até $3,8 \mathrm{~mm}$, lacínias do cálice triangulares

C. cupressinum

5. Flores 6-meras, pétalas rosa intenso, hipanto sem coroa radial de tricomas no ápice, fruto cápsula com deiscência da base para o ápice

Lavoisiera imbricata

4. Folhas não carenadas.

\section{Fruto baga.}

8. Inflorescências terminais.

9. Pétalas de ápice arredondado

Miconia

10. Face abaxial das folhas adultas glabra.

11. Folhas obovadas, anteras com quatro poros

M. theaezans

11. Folhas ovadas ou elípticas, anteras com um poro.

12. Face adaxial das folhas bulada, dois pares de nervuras acródromas suprabasais M. chamissois

12. Face adaxial das folhas não bulada, um par de nervuras acródromas basais.

13. Nós dos ramos com projeções interpeciolares semelhantes a estípulas M. cinnamomifolia

13. Nós dos ramos sem projeções interpeciolares semelhantes a estípulas M. ligustroides

10. Face abaxial das folhas adultas com indumento

14. Flores 4-meras

M. pepericarpa 14. Flores 5-meras.

15. Folhas lineares ou linear-lanceoladas, anteras com ápice truncado e 2 poros amplos.

M. cyathanthera

15. Folhas nunca lineares oulinear-lanceoladas, anteras com ápice nunca truncado,uniporadas

16. Folhas com margem distintamente serreada, anteras com poro muito amplo e semelhante a uma rima

M. sellowiana

16. Folhas com margem nunca distintamente serreada, poro nunca semelhante a uma rima.

17. Indumento hirsuto, face adaxial das folhas bulada, face abaxial setulosa 
17. Indumento não hirsuto, face adaxial não bulada, face abaxial não setulosa.

18. Face abaxial das folhas adultas com indumento mas com a superfície da lâmina visível M. rubiginosa

18. Face abaxial das folhas adultas inteiramente recoberta por indumento, superfície da lâmina nunca visível.

19. Folhas com até $61,0 \times 28,7 \mathrm{~cm}$, nervuras acródromas suprabasais

M. brunnea

19. Folhas com até $25,0 \times 12,0 \mathrm{~cm}$, nervuras acródromas basais.

20. Arvoreta ou arbusto robusto, folhas adultas com até $25,0 \times 12,0 \mathrm{~cm}$, face abaxial levemente ferrugínea

M. ferruginata

20. Nunca arvoreta, arbusto nunca robusto, folhas adultas com até $13,0 \times 6,0 \mathrm{~cm}$, face abaxial canescente.

21. Anteras brancas, baga verde-jade.....

M. albicans

21. Anteras amarelas, filetes e conectivos das anteras amarelos tornando-se vermelhos com o tempo, baga atropurpúrea.

22. Folhas ovadas a elípticas, pecíolos com até $0,6 \mathrm{~cm}$

M. fallax

22. Folhas lanceolado-ovadas a lanceoladas, pecíolos com 1,0-2,0 cm

9. Pétalas de ápice agudo....

M. stenostachya

23. Flores 6-meras, ovário 4-locular, folhas lanceoladas, lacínias do cálice e brácteas conferem cor rósea ou vermelha à inflorescência

L. melastomoides

23. Flores 5-meras, ovário 3-locular, folhas nunca lanceoladas, lacínias do cálice e brácteas nunca conferem cor rósea ou vermelha à inflorescência.

24. Folhas cordiformes, indumento hirsuto-glanduloso, tricomas glandulares de dois tipos: sésseis e pedunculados L. adenothrix

24. Folhas nunca cordiformes, indumento nunca hirsuto-glanduloso, tricomas nunca glandulares.

25. Hipanto e lacínias do cálice densamente recobertos por tricomas ocráceos, com muitas projeções laterais

L. pennipilis

25. Hipanto e lacínias do cálice nunca com esse tipo de indumento.

26. Anteras amarelas, folhas submembranáceas. L.australis

26. Anteras róseas a vináceas, folhas não submembranáceas.

27. Indumento hirsuto-tomentoso, hipanto oblongo-urceolado, purpúreo

L. polychaeta

27. Indumento viloso, estrigoso ou híspido.

28. Estames com filetes brancos, hipanto hirsuto

L. cancellata

28. Estames com filetes róseos a vináceos, indumento estrigoso ou viloso.

29. Indumento estrigoso, hipanto globoso ....L. coriacea

29. Indumento viloso, hipanto oblongo

L. aurea

8. Inflorescências axilares

30. Pétalas de ápice arredondado ou btuso

Clidemia sericea

7. Fruto cápsula.

30. Pétalas de ápice agudo...... Ossaea amygdaloides

31. Folhas com margem conspicuamente revoluta. 32. Pétalas roxas, estames conspicuamente dimorfos, conectivo prolongado abaixo das tecas das anteras Comolia sertularia 
32. Pétalas brancas, estames subisomorfos, conectivo não prolongado abaixo das tecas das anteras Marcetia taxifolia

31. Folhas com margem nunca conspicuamente revoluta.

33. Pétalas amarelas ou laranja com base amarela.

34. Subarbusto pouco ou não ramificado, folhas em pseudo-fascículos, flores com pétalas amarelas

Cambessedesia espora subsp.ilicifolia

34. Arbusto bastante ramificado, folhas opostas, flores com pétalas laranja de base amarela

Cambessedesia corymbosa

33. Pétalas rosa, roxas, lilases, púrpura ou brancas

35. Folhas com nervuras secundárias e terciárias não evidentes na face abaxial

Microlicia

36. Anteras poliesporangiadas (corrugadas).

37. Anteras vináceas no verticilo antessépalo e amarelas no verticilo antepétalo, folhas com indumento densamente viloso, canescente M. fasciculata

37. Anteras amarelas nos dois verticilos, folhas com indumento esparsamente hirsuto M. euphorbioides

36. Anteras não poliesporangiadas (lisas).

38. Plantas com indumento densamente hirsútulo, tricomas glandulares pedunculados M. glandulifera

38. Plantas com indumento nunca densamente hirsútulo, tricomas nunca glandulares pedunculados.

39. Planta apenas com pontuações glandulares, folhas com base truncada, ápice não apiculado nem aristado M. isophylla

39. Plantas com pontuações glandulares e tricomas simples, folhas com base nunca truncada, ápice aristado ou apiculado.

40. Folhas oblongo-elípticas, uninérvias, apenas com pontuações glandulares, margem levemente crenulada não ciliada, lacínias do cálice afastadas entre si, ápice aristado, base esparsamente setosa

M. avicularis

40. Folhas lanceolado-ovadas ou obovadas, nunca apenas com pontuações glandulares, margem inteira ou levemente serrilhada, ciliada, lacínias não afastadas entre si, ápice não aristado, base não esparsamente setosa.

41. Folhas lanceolado-ovadas, esparsamente pilosas a pilosas, margem levemente serrilhado-ciliada, pedicelos com até $0,5 \mathrm{~mm}$, lacínias do cálice largamente triangulares com 3,0 mm

M. decussata

41. Folhas obovado-oblongas, com raros tricomas simples, margem inteira curtamente ciliada, pedicelos com 1,0-2,0 mm, lacínias do cálice triangular-subuladas com 1,5-2,0 mm M. fulva

35. Folhas com nervuras secundárias e terciárias evidentes na face abaxial.

42. Anteras amarelas no verticilo antepétalo e vináceas no verticilo antessépalo Trembleya

43. Pétalas brancas com base vinácea, lacínias do cálice com $1,0 \mathrm{~mm}$, largamente triangulares T. parviflora

43. Pétalas rosa ou rosa intenso, lacínias do cálice com 3,0-4,0 $\mathrm{mm}$, estreitamente triangulares a triangular-subuladas.

44. Folhas glutinosas, ovadas a largamente elípticas, margem denteada no terço apical, pétalas rosa-intenso, folhas discolores

T. tridentata 
44. Folhas hirsuto-glandulosas, nunca ovadas, margem serreado-ciliada, pétalas levemente róseas a rosas, folhas concolores, verde-amareladas.

T. phlogiformis

42. Anteras bege, róseas, lilases ou roxas, em um ou nos dois verticilos, nunca amarelas no ciclo antepétalo e vináceas no ciclo antessépalo.

45. Prolongamento dos conectivos das anteras sem apêndice ventral.

46. Flores 5-meras, lacínias do cálice suborbiculares, filetes glabros, sem apêndice dorsal

Svitramia pulchra

46. Flores 4-meras, lacínias do cálice subuladas, filetes com tricomas glandulares curtos e robustos na face ventral e com apêndice dorsal bilobado..... Macairea radula

45. Prolongamento dos conectivos das anteras com apêndice ventral.

47. Ovário glabro, apêndices ventrais longamente bífidos na base dos prolongamentos dos conectivos anteras do ciclo antessépalo, curtamente bituberculados na base dos prolongamentos dos conectivos das anteras do ciclo antepétalo.....

Acisanthera variabilis

47. Ovário piloso no ápice, apêndices ventrais bituberculados ou bilobados na base dos prolongamentos dos conectivos dos dois verticilos das anteras

Tibouchina

48. Subarbustos.

49. Flores 4-meras, indumento hirsuto, anteras amarelas tornando-se vináceas com o tempo

T. herbácea

49. Flores 5-meras, indumento estrigoso a estrigoso-seríceo, anteras brancorosadas tornando-se vináceas com o tempo

T. gracilis

48. Arbustos a árvores.

50. Folhas geralmente triverticiladas, raro opostas, face adaxial glabra, filetes com tricomas glandulares longos apenas na face ventral

50. Folhas nunca triverticiladas, face adaxial com indumento, filetes glabros ou com tricomas nunca apenas na face ventral.

51. Pétalas lilases ou roxas com base branca que se torna vermelha com o tempo, face adaxial densamente serícea, face abaxial densamente seríceo-tomentosa T. heteromalla

51. Pétalas lilases, roxas ou púrpura com base nunca branca nem se tornando vermelha com o tempo, face adaxial nunca densamente serícea, face abaxial nunca densamente seríceo-tomentosa.

52. Folhas membranáceas, hipanto com $3,5 \mathrm{~mm}$, lacínias do cálice com $1,3 \mathrm{~mm}$

T. fothergillae

52. Folhas nunca membranáceas, hipanto com 5,0-8,0 mm, lacínias do cálice com 5,0-6,0 mm.

53. Arbusto, face adaxial da folha serícea

T. martialis

53. Arvoreta ou árvore, face adaxial da folha estrigosa.

54. Face adaxial das folhas bulada, tricomas com base ramificada

.T. estrellensis

54. Face adaxial das folhas nunca bulada, tricomas com base nunca ramificada.

55. Folhas lanceoladas com até 9,0 × 3,0 cm, lacínias do cálice com ápice agudo, apêndices ventrais com tricomas glandulares subsésseis T. candolleana

55. Folhas laceolado-ovadas com até 16,0 x 5,0 cm, lacínias do cálice com ápice obtuso, apêndices ventrais glabros 
Cambessedesia sp. é uma nova espécie, próxima a C. corymbosa DC., mas com diferenças bastante significativas, sendo até o momento restrita à Serra de São José (Alves et al., no prelo). Na Serra de São José, Chaetostoma cupressinum é endêmica (Koschnitzke \& Martins, 2006) e Chaetostoma albiflorum não foi mais encontrada desde a última coleta realizada por Alves em 1996. Esta espécie é bastante comum nas Serras de Ouro Grosso e Carrancas, próximas à Serra de São José.

Clidemia sericea D. Don apresenta distribuição pontual em apenas três locais da Serra de São José. No Brasil, parece ser uma espécie de distribuição bastante restrita, sendo encontrada em pouquíssimas localidades nos estados da Bahia, Minas Gerais e São Paulo (Drummond, 2005). Contudo, esta espécie apresenta uma interessante disjunção, sendo encontrada também nas Guianas Venezuelanas.

A ocorrência de Comolia sertularia Triana foi observada somente para o estado de Minas Gerais (Drummond, 2005). Embora a maioria das flores dessa espécie seja tetrâmera, na população da Serra de São José foram observadas, com freqüência, flores 5-6-meras. Desde as primeiras coletas, feitas há 19 anos, essa espécie tem apresentado, com o tempo, algumas alterações, como flores mais numerosas e de dimensões menores; além disso, a cor tem se tornado mais clara, mudando de roxoazulado para roxo-avermelhado. Entre as áreas comparadas, $C$. sertularia ocorre apenas na Serra de São José e na Serra do Cipó. Apesar de não ter sido citada na flora preliminar da Serra do Cipó, foi observada no herbário SPF uma coleta de Santana do Riacho, localizada naquela região.

Leandra australis (Cham.) Cogn., cuja distribuição era descrita desde o estado do Rio Grande do Sul até São Paulo, passa a ter sua ocorrência até o estado de Minas Gerais. Leandra pennipilis Cogn. é uma espécie de distribuição bastante restrita, ocorrendo apenas no estado de Minas Gerais. Apresenta disjunção entre a Serra de São José, São Tomé das Letras e também com a Serra Negra, município de Itamarandiba, citada na Flora Brasiliensis (Cogniaux, 1886-1888).
Microlicia avicularis (Naudin) Mart. e $M$. glandulifera Cogn. são espécies de distribuição restrita a poucas localidades do estado de Minas Gerais. Mesmo na Serra de São José, essas espécies têm ocorrência pontual. M. euphorbioides Mart. apresenta populações de flores brancas, rosa com base alva ou levemente róseas, mas que não ocorrem simultaneamente em nenhuma das áreas da Serra de São José.

Segundo Romero (1997), Siphanthera arenaria Cogn. ocorre em formações de campo limpo arenoso e campo úmido da Serra do Espinhaço. O limite sul da ocorrência dessa espécie passa a ser a Serra de São José, ultrapassando a Cadeia do Espinhaço (Drummond, 2005).

A Serra de São José é a localidade-tipo de Trembleya tridentata Naudin, apresentando população bastante significativa em diversas áreas. Essa espécie é restrita ao estado de Minas Gerais (Martins, 1997).

Talvez graças à maior afinidade geológica, o maior número de espécies em comum com a Serra de São José ocorre com a Serra da Canastra, e não com Carrancas, que é a área mais próxima. O menor número de espécies em comum, no Brasil, ocorre com Catolés. Em comum com as Guianas Venezuelanas foram encontradas oito espécies: Clidemia sericea, $M i$ conia albicans, M. fallax, M. ibaguensis, M. rubiginosa, M. stenostachya, M. theaezans e Tibouchina gracilis.

Uma significativa ação antrópica é claramente percebida em todas as áreas da Serra. O gado alcança locais inimagináveis, adubando o solo e, assim, modificando as condições primitivas e próprias para a manutenção e o desenvolvimento das espécies dos Campos rupestres e do Cerrado, além de contribuir para a instalação de espécies invasoras, principalmente de gramíneas trazidas para a região para formação de pasto. Essas espécies invasoras têm tomado áreas cada vez maiores, claramente diminuindo as populações das espécies nativas. O turismo ecológico, principalmente por intermédio de passeios a cavalo, também colabora com o mesmo tipo de ação. O mercado imobiliário, já dentro da APA, chega cada vez mais próximo à Serra, devastando extensas áreas para a construção de condomínios e pousadas ecológicas. 
A Serra de São José, com apenas $30 \mathrm{~km}$, apresenta grande riqueza de espécies de Melastomataceae se comparada com outras serras de área muito superior. A área da mata na encosta sul ainda não foi devidamente coletada e, certamente, mais espécies de Melastomataceae serão encontradas, aumentando ainda mais o conhecimento sobre a riqueza da Serra de São José.

Toda essa riqueza precisa urgentemente de proteção. A necessidade de planos de manejo para a utilização sensata e equilibrada dos recursos da Serra, educação ambiental para a população, os empresários e os turistas e leis eficientes de proteção se faz premente. Também é de primordial importância a conscientização de todos com relação ao privilégio de viver ou visitar um local tão precioso e tão bonito, mas que, sem ações objetivas e rápidas, pode ser irremediavelmente degradado, com perda irreparável para toda a população de Tiradentes e para a natureza.

\section{Agradecimentos}

Ao Museu Nacional/UFRJ e a seus professores, técnicos e funcionários por todo o apoio durante o Curso de Mestrado. Aos especialistas pela ajuda com algumas identificações. À SR2 e ao CNPq pelo apoio financeiro para esta pesquisa.

\section{REFERÊNCIAS BIBLIOGRÁFICAS}

Alves, R. J. V. 1997. Projeto Flora da Serra de São José. Museu Nacional \& EFLEX-Ritápolis. J. Tiradentes 2: 4.

Alves, R. J. V. 1992. The flora \& Vegetation of the Serra de São José in Minas Gerais, Brazil. Ph.D. thesis. Botanical Institute, Czechoslovak Academy of Sciences, Prague, $70 \mathrm{p}$.

Alves R. J. V., R. A. R. Drummond, \& A. B. Martins. (No prelo). A new species of Cambessedesia (Melastomataceae) from Brazil. Kew Bull.

Baumgratz, J. F. A., M. L. D. R. Souza, A. B. Martins, E. N. Lughandha \& E. M. Woodgyer. 1995. Melastomataceae. In: B.L. Stannard (Ed), Flora of the Pico das
Almas, Chapada Diamantina - Bahia, Brazil. p. 433-483, Royal Botanical Gardens, Kew.

Berry, P. E., K. Yatskievych \& K. B. Holst. 2001. Flora of the Venezuelan Guayana. v. 6. Missouri Botanical Garden, St. Louis.

Clausing, G. \& S. S. Renner. 2001. Molecular phylogenetics of Melastomataceae and Memecylaceae: implications for character evolution. Am. J. Bot. 88: 486-498.

Cogniaux, A. 1883-1885. Melastomataceae. Tribus Microlicieae e Tibouchinieae. In: C. P. F. Martius \& A. G. Eichler. (Eds), Flora brasiliensis. v. 14. F. Fleischer, Lipsiae.

Cogniaux, A. 1886-1888. Melastomataceae. Tribus Miconieae. In: C. P. F. Martius \& A. G. Eichler. (Eds), Flora brasiliensis. v. 14. F. Fleischer, Lipsiae.

Drummond, G. M., C. S. Martins, A. B. M. Machado, F. A. Sebaio \& Y. Antonini (Org.). 2005. Biodiversidade em Minas Gerais. 2. ed., Fundação Biodiversitas, Belo Horizonte. Disponível em: <http:/ / www.biodiversitas.org.br/atlas/mapasintese.asp >. Acesso em: 16 fev. 2005.

Drummond, R. A. R. 2005. Melastomataceae da Serra de São José, MG. Dissertação de Mestrado. Museu Nacional, Universidade Federal do Rio de Janeiro, Rio de Janeiro, $233 \mathrm{p}$.

Goldenberg, R. 2000. O gênero Miconia Ruiz \& Pav. (Melastomataceae): I. Listagens analíticas, II. Revisão taxonômica da seção Hypoxanthus (Rich. Ex. DC.) Hook. F. Tese de Doutorado. Universidade Estadual de Campinas, Campinas.

Guimarães, P. J. F. 1997. Estudos taxonômicos de Tibouchina sect. Pleroma (D.Don) Cogn. (Melastomataceae). Tese de Doutorado. Universidade Estadual de Campinas, Campinas, $191 \mathrm{p}$.

Holmgren, P. K., W. Keuken \& E. K. Schofield. 1990. Index herbariorum. Part I. The herbaria of the world. Regnum vegetabile. v. 106. Scheltema \& Holkema, Utrecht, 452 p.

Koschnitzke, C. \& A. B. Martins. 2006. Revisão taxonômica de Chaetostoma DC. (Melastomataceae, Microlicieae). Arq. Mus. Nac. 64: 95-119. 
Martins, A. B. 1984. Revisão taxonômica do gênero Cambessedesia DC. (Melastomataceae). Dissertação de Mestrado. Universidade Estadual de Campinas, Campinas, $191 \mathrm{p}$.

Martins, A. B. 1989. Revisão taxonômica do gênero Marcetia DC. (Melastomataceae). Tese de Doutorado. Universidade Estadual de Campinas, Campinas, $277 \mathrm{p}$.

Martins, A. B., J. Semir, R. Goldenberg \& E. Martins. 1996. O gênero Miconia Ruiz \& Pav. (Melastomataceae) no estado de São Paulo. Acta Bot. Bras. 10: 267-316.

Martins, E. 1997. Revisão taxonômica do gênero Trembleya DC. (Melastomataceae). Tese de Doutorado. Universidade Estadual de Campinas, Campinas, $162 \mathrm{p}$.

Matsumoto, K. 1999. A família Melastomataceae Juss. nas formações campestres do município de Carrancas, Minas Gerais. Dissertação de Mestrado. Universidade Estadual de Campinas, Campinas, 91 p.

Renner, S. S. 1989. Systematic studies in the Melastomataceae: Bellucia, Loreya and Macairea. Mem. New York. Bot. Gard. 50: 1-112.

Renner, S. S. 1990. A revision of Rhynchanthera (Melastomataceae). Nord. J. Bot. 9: 601-630.

Renner, S. S. 1993. Phylogeny and classification of the Melastomataceae and Memecylaceae. Nord. J. Bot. 13: 519-540.

Renner, S. S. 1994. A revision of Pterolepis (Melastomataceae: Melastomeae). Nord. J. Bot. 14: 73-104.

Ribeiro, A. 1996. Estratigrafia e paleoambientes nas sucessões metassedimentares proterozóicas das Serras do Lenheiro, São José e São João Del Rei, sul de Minas Gerais. Tese de Doutorado. Universidade Federal do Rio de Janeiro, Rio de janeiro, $167 \mathrm{p}$.

Romero, R. 1997. O gênero Siphanthera Pohl ex. DC. (Melastomataceae) no estado de Minas Gerais. Rev. Brasil. Bot. São Paulo 20: $175-183$.

Romero, R. 2000. A família Melastomataceae no Parque Nacional da Serra da Canastra, Minas Gerais, Brasil. Tese de Doutorado. Universidade Estadual de Campinas, Campinas, $326 \mathrm{p}$.

Semir, J., S. Chiea \& A. B. Martins. 1987. Melastomataceae. In: A. M. Giulietti, N. L. Menezes, J. R. Pirani, M. Meguro \& M. G. L. Wanderley (Orgs), Flora da Serra do Cipó, Minas Gerais: caracterização e lista das espécies. Bol. Bot. Univ. São Paulo 9: 72-78.

Souza, M. L. D. R. 1998. Revisão taxonômica do gênero Ossaea DC. (Melastomataceae) no Brasil. Tese de Doutorado. Universidade de São Paulo, São Paulo, 317 p.

Zappi, D. C., E. Lucas, B. L. Stannard, E. N. Lughanda, J. R. Pirani, L. P. de Queiroz, S. Atkins, D. J. N. Hind, A. M. Giulietti, R. M. Harley \& A. M. de Carvalho. 2003. Lista das Plantas Vasculares de Catolés, Chapada Diamantina, Bahia, Brasil. Bol. Bot. Univ. São Paulo 21: 345-398.

Recebido em 06.II.2006 Aceito em 30.XI.2007 